\title{
Confocal Raman spectroscopy to monitor intracellular penetration of $\mathrm{TiO}_{2}$ nanoparticles
}

\author{
Hamideh Salehi, ${ }^{a *}$ Isabelle Calas-Bennasar, ${ }^{a}$ Jean-Cédric Durand, ${ }^{a}$ \\ Elodie Middendorp, ${ }^{a}$ Jean Valcarcel, ${ }^{\text {a }}$ Christian Larroque, ${ }^{b}$ Katalin Nagy, ${ }^{c}$ \\ Kinga Turzó $\mathrm{K}^{\mathrm{c}}$ Imre Dekany ${ }^{\mathrm{d}}$ and Frédéric J. G. Cuisinier ${ }^{\mathrm{a}}$
}

\begin{abstract}
Confocal Raman microscopy, a noninvasive, label-free, and high-spatial resolution imaging technique, in combination with $K$-mean cluster analysis and a correlation coefficient map, was employed to trace titanium dioxide $\left(\mathrm{TiO}_{2}\right) \mathrm{nanopar-}$ ticles in living MCF-7 and TERT cells. The penetration of $\mathrm{TiO}_{2}$ nanoparticles into cells revealed a gradual time-dependent diffusion of nanoparticles over the entire cell. Cell apoptosis was monitored by tracing cytochrome c diffusion into the cytoplasm. A comparison with the mitochondrial clustering indicated that cytochrome $c$ was inside the mitochondria for $\mathrm{TiO}_{2}$ concentration of $2 \mu \mathrm{g} \mathrm{ml}^{-1}$. This result demonstrates that the presence of $\mathrm{TiO}_{2}$ particles within a cell does not induce apoptosis. We demonstrated that confocal Raman microscopy allow to follow penetration of $\mathrm{TiO}_{2}$ particles in cell and to monitor the apoptotic status of the penetrated cells. Copyright $\odot 2014$ John Wiley \& Sons, Ltd.
\end{abstract}

Keywords: titanium dioxide; Raman microscopy; K-mean cluster; correlation coefficient; cell imaging

\section{Introduction}

Nanoparticles' wide use in domains spanning from cosmetics to medical implants raised the concern of their toxicity. Entrance of engineered nanoparticles into the circulation of the respiratory or the gastrointestinal tract can threaten the health. ${ }^{[1]}$ Therefore in nanotoxicology, a new research discipline has been recently evolved to deal with the health issues relating to the nanoparticles that recently appeared. ${ }^{[2]}$ The nanoparticles' uptake into cells is facilitated because of their small size. The blood and lymph circulation helps them to reach sensitive target sites such as bone marrow, lymph nodes, spleen, and heart and then cross epithelial and endothelial cells through transcytosis. ${ }^{[2]}$ Titanium dioxide $\left(\mathrm{TiO}_{2}\right)$ has been used for many years as a white pigment in paints, toothpastes, and food (E171 colorant). Large-scale engineering of nano-sized $\mathrm{TiO}_{2}$ powders boosted their use in daily life, and we find them in sunscreens and various cosmetics. ${ }^{[3]}$ Titanium (Ti) and its alloys are widely used materials for orthopedic and dental implants. ${ }^{[4,5]}$ Previous reports stress that lose of metal particles can be generated at the bone-implant interface during the insertion procedure, ${ }^{[6]}$ and they are covered with crystalline (both anatase and rutile) and amorphous particles. ${ }^{[7]}$ Serious diseases could be encountered from exposure to $\mathrm{TiO}_{2}$ as the lung cancer risk studied by Boffetta et al. ${ }^{[8]}$

The toxicokinetics of a nanomaterial depends on the particle size and shape, its agglomeration, hydrophobicity, surface charge, and protein-binding capacity. ${ }^{[9]} \mathrm{TiO}_{2}$ nanoparticles in the cytoplasm can interact with proteins and affect their crucial functions in different tissues. ${ }^{[10]}$ A distinct cytotoxic effect on HeLa cells has been observed in vitro with photo-excited $\mathrm{TiO}_{2}$ particles, and the tumor growth of HeLa cells has been shown to be significantly inhibited by treatment with $\mathrm{TiO}_{2}$ particles and UV irradiation. ${ }^{[11]}$

One of the major concerns regarding the possible toxic effect of nanoparticles is their cell penetration capacity. ${ }^{[9]}$ Conventional in vitro cytotoxicity assays allow the analysis of effects on proliferation, viability, metabolic activity, and liposomal and mitochondrial activity. ${ }^{[12]}$ However, these methods do not provide the subcellular distribution of $\mathrm{TiO}_{2}$ within the cells. Transmission electron microscopy has been used to detect nanoparticles within fixed and embedded cells because of its high-resolution power. ${ }^{[13]}$ Imaging cells exposed to fluorescently labeled nanoparticles using confocal fluorescence microscopy is one of the mostly used methods to track nanoparticles in a fixed cell. ${ }^{[14]}$ However, labeled nanoparticles could release dye into the surrounding environment, so the distribution of fluorescence does not necessarily represent the distribution of nanoparticles. Furthermore, it is unclear whether the transport mechanism for labeled nanoparticles is the same as that for unlabeled nanoparticles. ${ }^{[15]}$ Flow cytometry was also proposed as a method to follow nanometersized particle into cells and confirmed by dark-field microscopy. ${ }^{[16,17]}$ Light-scattering techniques, such as dark-field microscopy and flow cytometry, enable the quantification of light-reflective nanomaterials within cells but could not discriminate between different materials. ${ }^{[18]}$

* Correspondence to: Hamideh Salehi, Laboratoire Biologie-Santé Nanosciences, EA 4203, UFR Odontologie, Université Montpellier 1, Montpellier 34193, France. E-mail:s_hamideh@yahoo.com

a Laboratoire Biologie-Santé Nanosciences, EA 4203, UFR Odontologie, Université Montpellier 1, Montpellier 34193, France

b IRCM/INSERM896, Centre Régional de Lutte contre le Cancer Val d'Aurelle - Paul Lamarque, Université Montpellier 1, Montpellier 34298, France

c Faculty of Dentistry, University of Szeged, Tisza Lajos krt. 64, 6720, Szeged, Hungary

d Hungarian Academy of Sciences, MTA-SZTE Supramolecular and Nanostructured Materials Research Group, H-6720, Szeged Dóm tér 8, Hungary 
Alternatively, confocal Raman microscopy appears to be a unique tool for chemical cell imaging. ${ }^{[19,20]}$ The main advantages of confocal Raman microscopy include a high-spatial resolution and a unique compositional sensitivity intrinsic to Raman spectroscopic methods. ${ }^{[21]}$ The finger print region and $\mathrm{CH}$ band Raman signals contain enough information to separate cell organelles. Raman spectral signatures are being used to identify cell components such as the nucleus, the endoplasmic reticulum, and the mitochondria. ${ }^{[22,23,21,24]}$ The Raman signals of cellular composition and subcellular organelles, with a spatial resolution as good as fluorescence microscopy, make Raman microscopy a powerful candidate to visualize cell organelles and trace drugs and particles intracellularly. Tracing drugs within cells no longer requires a label because the drug's Raman signature enables its detection in the cell. Therefore, Raman confocal microscopy appears to be a promising tool for tracking nanoparticles in cells as the Raman image is not based on optical contrast or fluorescence but on the chemistry of the nanoparticles.

After cell penetration, $\mathrm{TiO}_{2}$ nanoparticles induce a timedependent and dose-dependent decrease in cell viability and cause apoptosis. ${ }^{[25-27]}$ Apoptosis (programmed cell death) is a cellular self-destruction mechanism that is essential for a variety of biological events, such as developmental sculpturing, tissue homeostasis, and the removal of unwanted cells. Mitochondria play a crucial role in regulating cell death. ${ }^{[21,28]}$ There are multiple initiators of apoptosis to instigate the cascade of events leading to activation of a series of cytoplasmic proteases named caspases (cysteinylaspartate-specific proteinases). Caspases are activated through the extrinsic and/or intrinsic pathways. The extrinsic pathway is activated by cell surface death receptors, while the intrinsic pathway is initiated by the formation of the cytosolic apoptosome composed of Apaf-1, procaspase 9, and the cytochrome c released from mitochondria. ${ }^{[29]}$ Light and fluorescent microscopies are traditional instruments to detect apoptosis by their cells' reduced size, cell membrane blebbing/budding, and loss of normal nuclear structure features because of nuclear fragmentation and condensation. In fluorescent microscopy, different dyes such as 4',6diamidino-2-phenylindole or propidium iodide can be applied to detect apoptosis and different fluorescent-labeled antibodies of specific apoptotic activators or initiators. ${ }^{[30]}$

In this work, we employ Raman microscopy to monitor $\mathrm{TiO}_{2}$ nanoparticles uptake within cells, in parallel with visualizing the mitochondria and cytochrome $\mathrm{c}$ in the same cell without the use of any labeling. Our paradigm is that if the cytochrome $\mathrm{c}$ is present outside of the mitochondria, this is an indication that apoptosis via a mitochondrial apoptosis pathway independent of the initiated caspase $8 /$ t-Bid pathway. ${ }^{[31]}$ It is known that the cell can respond to chemicals and nanoparticles by undergoing apoptosis, necrosis, or other cellular changes. ${ }^{[32]}$ There is a need to understand these cellular processes that are stimulated by nanoparticles. We attempted to demonstrate the possibility of detecting apoptosis in cells solely with post-measurement data analysis, which, to our knowledge, has not been previously reported. Confocal Raman microscopy appears to be the unique method enabling with a single acquisition to assess the presence and distribution of nanoparticle and/or drug and to determine the apoptosis status of living cells. ${ }^{[33]}$ Our aim was to demonstrate that confocal Raman microscopy allows to monitor $\mathrm{TiO}_{2}$ particles' intracellular distribution and simultaneously track the cytoplasmic localization of cytochrome $c$ and, thus, to determine whether cytochrome $c$ is released from mitochondria. In low concentration of $\mathrm{TiO}_{2}$, no sign of cytochrome c release was detected.

\section{Materials and methods}

\section{Cell culture}

The two cell lines selected are epithelial cell lines. TERT is an immortalized human oral keratinocyte cell line, and MCF-7 cells retained several characteristics of differentiated mammary epithelium. ${ }^{[34]}$ MCF-7 cells were grown in $75 \mathrm{~cm}^{2}$ tissue culture flasks (VWR, Strasbourg, France) in $7 \mathrm{ml}$ of Dulbecco's modified eagle's medium (DMEM) (Thermo Fisher, Strasbourg, France) containing 20\% FBS and $1 \%$ antibiotics (streptomycin $100 \mu \mathrm{g} \mathrm{ml}^{-1}$ and penicillin $100 \mathrm{U}$ $\mathrm{ml}^{-1}$ ) at $37^{\circ} \mathrm{C}$ and $5 \% \mathrm{CO}_{2}$. For experiments, the cells were seeded onto polished calcium fluoride $\left(\mathrm{CaF}_{2}\right)$ substrates (Crystran Ltd., Dorset, UK) and incubated for $24 \mathrm{~h}$ to allow for cell adhesion.

The immortalized epithelial human oral keratinocyte cell line (OKF6/TERT-2) was provided by J. Rheinwald and the Cell Culture Core of the Harvard Skin Disease Research Center (Boston, MA, USA). The cells were cultured in keratinocyte serum-free medium (KSFM) (Thermo Fisher, Strasbourg, France) containing $25 \mathrm{mg} \mathrm{ml}^{-1}$ of bovine pituitary extract, $5 \%$ penicillin/streptomycin, $0.2 \mathrm{ng} \mathrm{ml}^{-1}$ EGF (epithelial growth factor), $0.1 \%$ bovine serum albumin, and $0.3 \mathrm{mmolI}^{-1} \mathrm{CaCl}_{2}$. The cells were cultivated on a $\mathrm{CaF}_{2}$ substrate and incubated in a solution of DMEM containing $\mathrm{TiO}_{2}\left(2 \mu \mathrm{g} \mathrm{ml}^{-1}\right.$ or $1 \times 10^{15}$ nanoparticles per $\mathrm{ml}$ ) and rinsed with PBS prior to transferring to the confocal Raman microscope. After rinsing the cells with PBS, they were kept in $5 \mathrm{ml}$ PBS and transferred directly to do the Raman measurement. The Raman imaging was performed in room temperature. The MCF-7 cells were incubated for $3 \mathrm{~h}$, and the TERT cells were incubated for $3,6,9,12$, and $24 \mathrm{~h}$ to reveal the time-dependent gradual diffusion of $\mathrm{TiO}_{2}$ inside the cells. The total number of cell experiments is 32 .

\section{$\mathrm{TiO}_{2}$ nanoparticle preparation}

Aeroxide ${ }^{\circledast}$ P25 (Degussa, Dusseldorf, Germany) particle were selected as model of particles used in food, cosmetics, and medical devices. The anatase rutile fractions of P25 nanoparticles are ranging from $73 \%$ to $85 \%$ for anatase, $14 \%$ to $17 \%$ for rutile, and $0 \%$ to $18 \%$ for amorphous $\mathrm{TiO}_{2}{ }^{[35,36]}$

The P25 with particle size less than $25 \mathrm{~nm}$ was suspended in pure distilled deionized water. The BET specific area of $\mathrm{TiO}_{2}$ is $52 \mathrm{~m}^{2} \mathrm{~g}^{-1}$. The colloidal suspension was held in an ultrasonic bath at $20 \mathrm{kHz}$ (Sonifier 250, Branson, USA) for $10 \mathrm{~min}$. We select dynamic light scattering (DLS) for evaluating particle size in solution. DLS is a widely used technic yielding relatively accurate and consistent results very fast ${ }^{[37]}$ via measuring particle size from fluctuations in a scattered light intensity because of the Brownian movement of the particles. A Malvern Zetasizer Nano ZS (Malvern Ltd, Worcestershire, UK) was used to measure the particle size and distribution. The measured size of particle aggregates suspended in pure distilled, DMEM and KSFM, were determined. In water, the mean particle size was approximately $220 \mathrm{~nm}$. The aggregates size remained constant after $1 \mathrm{~h}$ and after 1 week, indicating the stability of the suspension (Table 1). In culture media as DMEM or KSFM, the aggregate diameters are, respectively, 416 and $393 \mathrm{~nm}$.

\section{Raman data acquisition}

The Raman spectra were collected using a Witec Confocal Raman Microscope System alpha 300R (Witec Inc., Ulm, Germany). The excitation for the confocal Raman microscope was provided by a frequency doubled Nd:YAG laser (Newport, Evry, France) at a wavelength of $532 \mathrm{~nm}$, with $50 \mathrm{~mW}$ laser output power in a single 


\begin{tabular}{|lcc|}
\hline \multicolumn{2}{l}{ Table 1. $\mathrm{TiO}_{2}$ particles stability } & \\
Time after ultrasonication & Particle size/nm & Size distribution (\%) \\
\hline \multirow{2}{*}{$1 \mathrm{~min}$} & 219 & 95.2 \\
& 4788 & 4.8 \\
$1 \mathrm{~h}$ & 240 & 98 \\
& 5067 & 2 \\
1 week & 220 & 97.8 \\
& 4808 & 2.2 \\
\end{tabular}

longitudinal mode. The light was carried to the microscope by a single fiber (diameter of $125 \mu \mathrm{m}$ ). The incident laser beam was focused onto the sample through a $60 \times$ water immersion objective with a numerical aperture of 1.0 and a working distance of $2.8 \mathrm{~mm}$ (Nikon, Tokyo, Japan). The Raman probe size determined using the water immersion objective $60 \times$ has a diameter of $0.4 \mu \mathrm{m}$. The Raman backscattered radiation mixed with the Rayleigh scattered light was then passed through an edge filter to block the Rayleigh light. With the assumption that most of the Rayleigh light was filtered, the entire light was passed through to a multimode mode fiber $(50 \mu \mathrm{m})$ directed to the electron multiplying charge coupled device camera (DU 970 N-BV353, Andor, Hartford, USA). The electron multiplying charge coupled device chip size was $1600 \times 200$ pixels, the camera controller was a 16 bit A/D converter operating at $2.5 \mathrm{MHz}$, and the camera was cooled by a Pelletier system. The UHTS 300 spectroscopy system with a 70\% throughput transmission and a $600 \mathrm{Imm}^{-1}$ grating (operating at $-60^{\circ} \mathrm{C}$ ) provides a spectral resolution of $3-5 \mathrm{~cm}^{-1}$. The acquisition time of a single spectrum was set to $0.5 \mathrm{~s}$. For control experiments, $150 \times 150$ points per image were recorded using a piezoelectric table, leading to a total of 22500 spectra for one image, with each spectrum corresponding to a spatial unit defined as a voxel. The spatial resolution of the system is calculated by the formula $d=\frac{1.22 \lambda_{\text {laser }}}{2 N A}$, which, in our system, is $325 \mathrm{~nm}^{[38]}$

The data acquisition and processing were performed using the IMAGE PLUS software from Witec. The data acquisition time for an image was approximately $4 \mathrm{~h}$ because of the displacement of the scan table. TERT cell imaging was performed with a lower integration time of $1.5 \mathrm{~h}$. The laser power on the sample was estimated to be less than $15 \mathrm{~mW}$. The photobiological effect of the laser light on cells and tissues originates from light absorption by endogenous chromophores, and hence, it depends on the wavelength of light source and cell type. For a $514 \mathrm{~nm}$ laser, the irradiation power is considered harmless for fixed lung epithelial cells less than $12 \mathrm{~mW}^{[18]}$ Moreover, long-time (until $48 \mathrm{~h}$ ) low-power laser irradiation with $532 \mathrm{~nm}$ laser was recently reported to increase human-derived glioblastoma cells proliferation, ${ }^{[39]}$ whereas shorttime irradiation (30-60s) at the same wavelength increases the proliferation rate of adipose tissue-derived stem cells. ${ }^{[40]}$ Therefore, it was important to control the effect laser irradiation in our experimental conditions. Control experiments, without nanoparticles, were realized on MCF7 cells, and no visible thermal or irradiation damages were noted. We monitored the effect of $532 \mathrm{~nm}$ laser on cell morphology, attachment (cell death induce cell detachment), and physiology. MCF7 cells cultured on $\mathrm{CaF}_{2}$ without any $\mathrm{TiO}_{2}$ injection were placed under laser light for long integration times (up to $4 \mathrm{~h}$ ). Data analysis shows no release of cytochrome c in cytoplasm. Cytochrome $\mathrm{c}$ release is observed during cell death. ${ }^{[41]} \mathrm{At}$ the end of experiments, the MCF7 cells are still adherent on $\mathrm{CaF}_{2}$ substrate, and no visual damage was observed.

\section{Data analysis}

The data analysis was based on three methods.

The first method utilized integrated Raman vibration mode intensities in specific regions. The $\mathrm{CH}$ stretching mode is one of the vibrational modes of the $\mathrm{CH}$ groups and one of the most intense Raman mode found in cells. CHs are abundant in protein, lipid, and carbohydrate, and the image based on the intensity of this band provides a pseudo map of protein, lipid, and carbohydrate concentration in cells. ${ }^{[42]}$ Each image based on these integrated intensities provided a map of the region. Using a reference table, the bright yellow hues were determined to indicate the highest intensities, and the orange hues, the lowest integrated intensities of the chosen region.

The second method was a K-mean cluster analysis (KMCA). $K$-mean clustering is an unsupervised algorithm that solves the clustering problems. ${ }^{[43]}$ The procedure follows a way to classify a given data set through a certain number of clusters (assume $k$ clusters). The main idea is to define $k$ centroids, one for each cluster. These centroids should be placed as much as possible far away from each other. The next step is to take each point belonging to a given data set and associate it to the nearest centroid. When no point is pending, the first step is completed, and the first grouping is finished. At this point, we need to recalculate $k$ new centroids from the previous step. After positioning these $k$ new centroids, a new binding has to be carried out between the same data set points and the nearest new centroid. A loop is being generated. As a result of this loop, we may notice that the $k$ centroids change their location step by step until no more changes are needed. ${ }^{[44]}$ In other words, centroids do not move any more. Finally, this algorithm aims at minimizing an objective function, in this case a squared error function. The objective function is defined as

$$
J=\sum_{j=1}^{k} \sum_{i=1}^{n}\left\|S_{i}^{(j)}-m_{j}\right\|^{2}
$$

Where $\left\|S_{i}^{(j)}-m_{j}\right\|^{2}$ is a chosen distance measured between a data point $S_{i}^{(j)}$ and the cluster center $m_{j}$ and is an indicator of the distance of the $n$ data points from their respective cluster centers. The $k$-mean algorithm does not necessarily find the most optimal configuration, corresponding to the global objective function minimum, although it can be proved that the procedure will always terminate. The algorithm is also significantly sensitive to the initial randomly selected cluster centers. To reduce this effect, the $k$-mean algorithm can be ran multiple times. Among all the clustering methods, the $K$-mean cluster method requires the least processing time. The KMCA was performed using the Witec Project Plus (Ulm, Germany) software.

The third method uses correlation coefficients to analyze data sets. A spectral correlation matrix was calculated to find the most similar spectrum to the reference spectrum of cytochrome c. ${ }^{[45]}$

Table 2. Cells $\mathrm{TiO}_{2}$ uptake after $3,6,9,12$, and $24 \mathrm{~h}$ incubation

\begin{tabular}{lcc|}
$\begin{array}{l}\text { Incubation time } \\
\text { with } \mathrm{TiO}_{2}(\mathrm{~h})\end{array}$ & $\begin{array}{c}\text { Cells with } \mathrm{TiO}_{2} \text { positives/total } \\
\text { number of cells }\end{array}$ & $\%$ \\
\hline 3 & $7 / 33$ & 21 \\
6 & $13 / 23$ & 56 \\
9 & $19 / 39$ & 48 \\
12 & $12 / 20$ & 60 \\
24 & $13 / 14$ & 92 \\
\hline
\end{tabular}




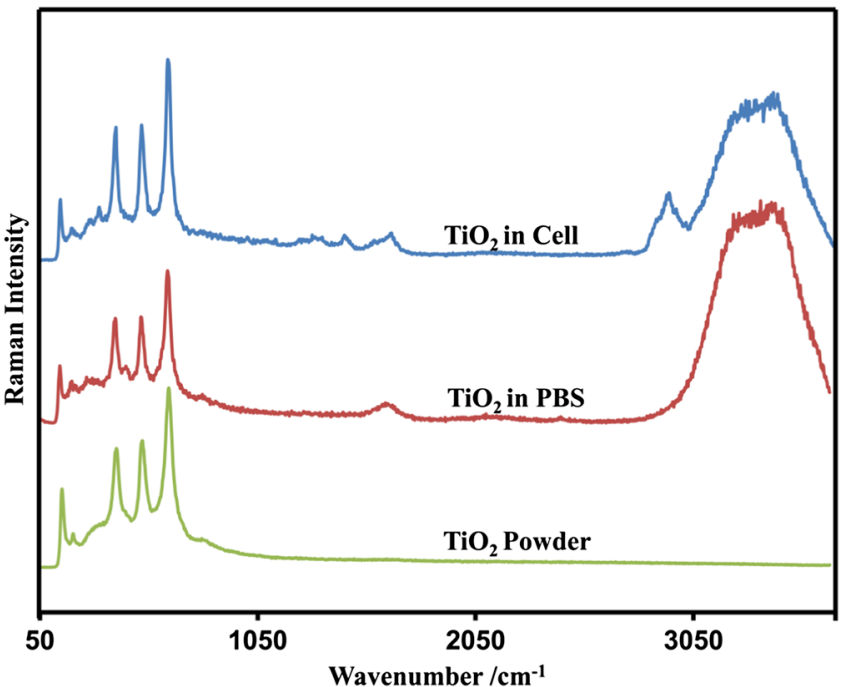

Figure 1. Raman spectra of $\mathrm{TiO}_{2}$ powder Aeroxide ${ }^{\oplus} \mathrm{P} 25$ (Green), $\mathrm{TiO}_{2}$ in $\mathrm{PBS}$ (red). Average spectrum of $\mathrm{TiO}_{2}$ in cells from $\mathrm{K}$-mean cluster analysis (blue).

To quantify the similarity as a 'distance', the Pearson's correlation coefficient was calculated for each pair of spectra, according to the following formula:

$$
r=\frac{\sum_{i=1}^{N}\left(\left(x_{i}-X\right)\left(y_{i}-Y\right)\right)}{\sqrt{\sum_{i=1}^{N}\left(x_{i}-X\right)^{2} \sum_{i=1}^{N}\left(y_{i}-Y\right)^{2}}}
$$

Where $N$ is the number of points within the spectrum, $x_{i}$ and $y_{i}$ are the individual points, and $X$ and $Y$ are the mean value of each spectrum. The value of $r$ can vary between -1 and 1 , thus it can be expressed as a percentage ranging from $-100 \%$ forno correlation, to $100 \%$, the perfect match. From these values, a pseudo-color map was constructed, reflecting the quantified similarities. All correlation calculations were performed with a homemade code written in MATLAB (Math Works, Inc, Massachusetts, USA).

\section{Results}

\section{$\mathrm{TiO}_{2}$ nanoparticles}

The $\mathrm{TiO}_{2}$ aggregates stability and particle size distribution are presented in Table 1. DLS measurement shows that immediately after suspension preparation, $95.2 \%$ of $\mathrm{TiO}_{2}$ aggregates have a diameter size of $219 \mathrm{~nm}$, and they rest stable even after 1 week (Table 1). The suspension in distilled water contains less aggregates and more stabilized suspension. In culture media as DMEM or KSFM, the aggregate diameters are 416 and $393 \mathrm{~nm}$, respectively.

The uptake of $\mathrm{TiO}_{2}$ into cells in function of the incubation time with the nanoparticles is presented in Table 2. There is an increase in the number of cells with intracellular $\mathrm{TiO}_{2}$ over time. After $24 \mathrm{~h}$ of incubation with $2 \mu \mathrm{g} \mathrm{ml}^{-1} \mathrm{TiO}_{2}$, nanoparticles were present in $92 \%$ of the cells, while after $3 \mathrm{~h}$, only $21 \%$ had nanoparticles. To trace $\mathrm{TiO}_{2}$ in cells, the first step was to analyze pure nanoparticles by Raman spectroscopy. In Fig. 1, the spectra of $\mathrm{TiO}_{2}$ powder (green), $\mathrm{TiO}_{2}$ in PBS (red), and $\mathrm{TiO}_{2}$ in cells (blue) are presented. The main peaks in the spectrum corresponding to cells are in the range of $700-1800 \mathrm{~cm}^{-1}$, while the $\mathrm{TiO}_{2}$ peaks are, before, at $700 \mathrm{~cm}^{-1}$. There is no overlap between the cellular peaks and these $\mathrm{TiO}_{2}$ peaks.

Figure 2 illustrates the data acquisition and analysis used for the intracellular detection of the nanoparticles. The low contrast in the
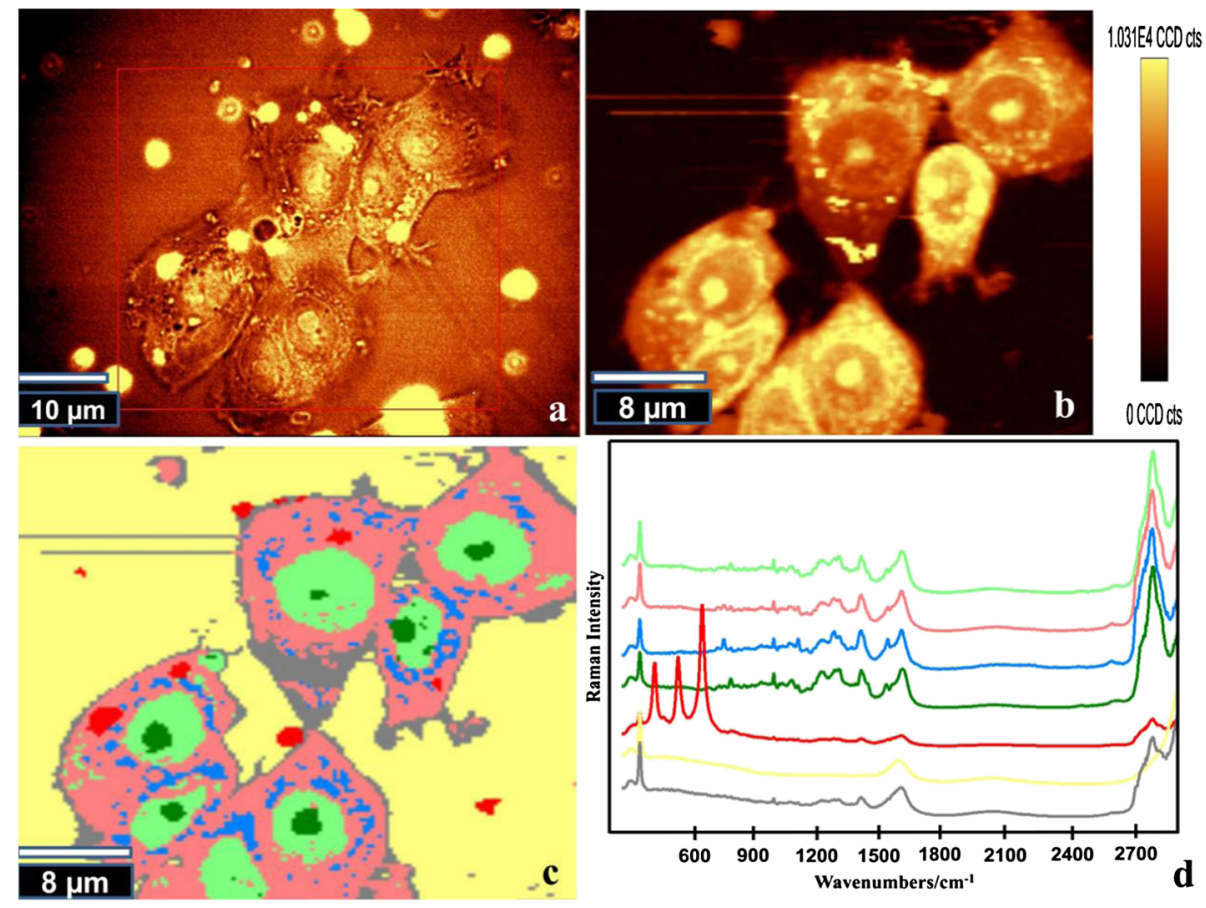

Figure 2. (a) Bright-field microscopic image of MCF-7 cells in buffer solution, $60 \times$ objective. (b) Integrated Raman intensities in the $2800-3000 \mathrm{~cm}^{-1}$ region of the cells shown in Fig. 2(a) collected at a dwell time of $0.5 \mathrm{~s} /$ point and a point spacing of around $300 \mathrm{~nm}$. Bright yellow and dark hues indicate the highest and the lowest integrated $\mathrm{CH}$ stretching intensities, respectively. A scale bar next to Fig. $2 \mathrm{~b}$ indicates the relevant intensity for each color. (c) Seven clusters of various cellular components obtained via KMCA, the clusters are based on data shown in B and correspond to the Raman spectra regions of 500-1800 and $2600-3200 \mathrm{~cm}^{-1}$. (d) Average spectra corresponding to the clusters in panel a. (Same colors as in c: the average spectra of the nucleus (light green) nucleolus (dark green), cytoplasm (pink), membrane (gray), mitochondria (blue), PBS buffer (yellow), and $\mathrm{TiO}_{2}$ (red)). 
bright-field image is due to the absence of staining of the living MCF-7 cells in the PBS solution (Fig. 2(a)). The total integrated Raman intensities of the $\mathrm{CH}$ stretching mode in the $2800-3000 \mathrm{~cm}^{-1}$ domain give an image representing the quantity of proteins and lipids and carbohydrates (Fig. 2(b)). The band at $2800-3000 \mathrm{~cm}^{-1}$ belongs to $\mathrm{CH}$, which is present in lipids, proteins, and carbohydrates and which could be found in every cell organelle. Hence, construction of an image using this range could present an intracellular view compared with bright-field image. When the intensity of the $\mathrm{CH}$ peak is low, the color in the image is dark, whereas a $\mathrm{CH}$ line with maximum intensity is shown in a yellow color. To make it clear, a scale bar is added to the image indicating the color intensities. The bright yellow hues correspond to high intensities of the $\mathrm{CH}$ stretching band, inside the cell, and the dark hues correspond to the lowest integrated intensities of the $\mathrm{CH}$ stretching band derived from the PBS. A scale bar next to the Raman image in Fig. 2(b) indicates the relevant $\mathrm{CH}$ intensities of each color. This image corresponds closely to the bright-field optical image. The image formed by seven clusters is also presented. The localization of the seven clusters calculated by the KMCA corresponds to specific areas of the cell. The cluster with the light green color corresponds to the nucleus, the cluster
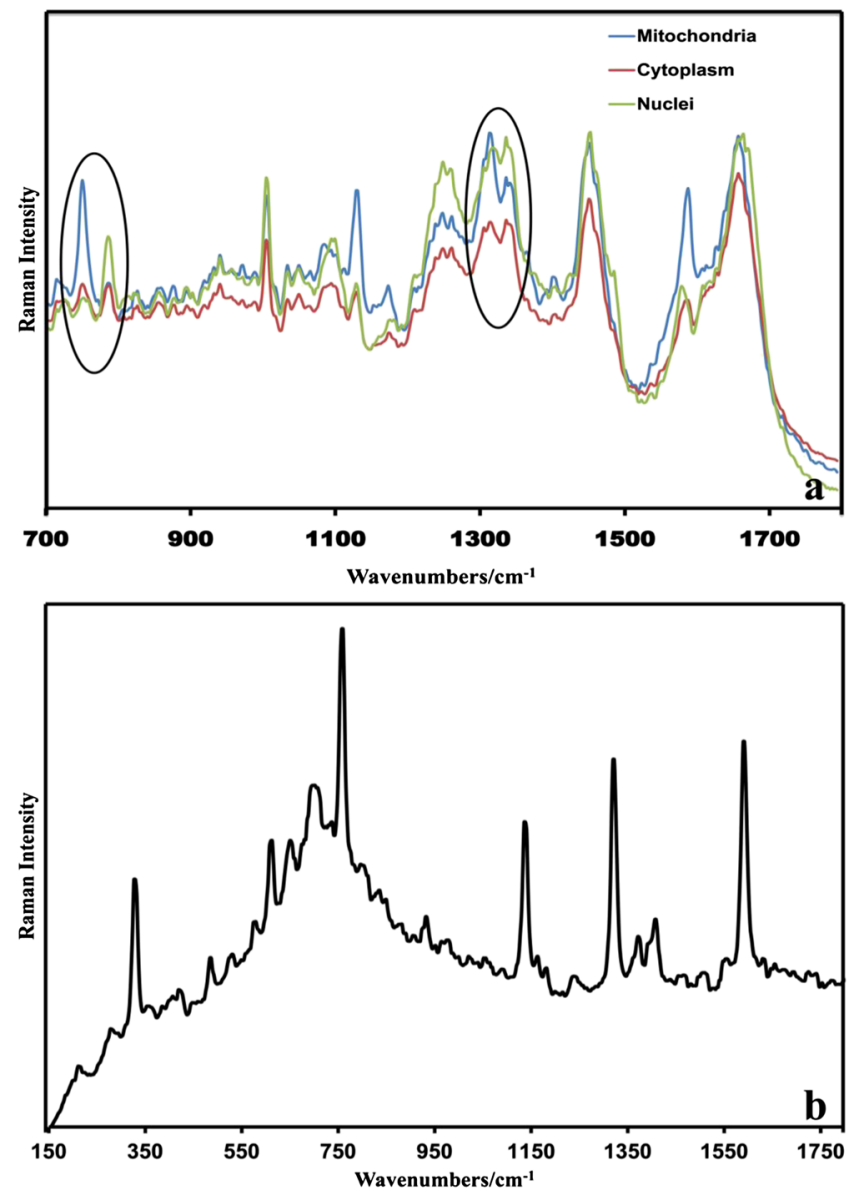

Figure 3. (a) Raman spectra of nucleus (green), cytoplasm (red), and mitochondria (blue) in cells obtained from $K$-mean cluster analysis. The average standard deviation of the spectra in three area nuclei, mitochondria, and cytoplasm are calculated. The average standard deviation calculated for cytoplasm (8 counts), mitochondria (13 counts), and nuclei (7 counts) and the intensities of whole spectra collected in this scan are 900 counts.' (b) Reference Raman spectrum of cytochrome c solution ( $\left.2 \mathrm{mg} \mathrm{ml}^{-1}\right)$, reduced with ascorbic acid. with the dark green color corresponds to the nucleolus, the cluster with the pink color corresponds to the cytoplasms, and, finally, the cluster with the light blue color corresponds to the mitochondria (Fig. 2(c)). The mean spectra of the seven clusters obtained by KMCA are shown in Fig. 2(d). The red spectrum corresponds closely to the Raman spectrum of $\mathrm{TiO}_{2}$ (Fig. 1), suggesting that the red color in Fig. 2(c) indicates the presence of $\mathrm{TiO}_{2}$. The intracellular red dots, representing $\mathrm{TiO}_{2}$ nanoparticles, are randomly distributed throughout the cytoplasm and in the vicinity of the cytoplasmic membrane. The detailed average spectra of the cytoplasm, nuclei, and mitochondria calculated by the KMCA are shown Fig. 3(a). The number of spectra contributing to the average spectrum of each cluster is in the order of thousands: $22500(150 \times 150)$ spectra are collected as shown in Fig. 2. KMCA divided all these spectra to seven categories; therefore, each cluster spectrum is the average of more than thousands of single spectrum. Consequently, the observed signal-to-noise ratio for an average spectrum is very good. The two black ellipses indicate Raman bands of the mitochondria. Because the KMCA allowed for the separation of a mitochondria cluster, our next step was to detect cytochrome $c$ in the cells. Cytochrome $\mathrm{c}$ acts as a trigger for the activation of the caspase cascade, and its release from mitochondria is a sign of apoptosis. A cytochrome c (Sigma-Aldrich, France) solution, reduced with ascorbic acid, was applied as a reference spectrum for the correlation coefficient mapping. ${ }^{[46,47]}$ The Raman spectrum of reduced cytochrome $\mathrm{c}$ is presented in Fig. 3(b).

A composite image of MCF-7 cells incubated with $2 \mu \mathrm{g} \mathrm{ml}^{-1}$ of $\mathrm{TiO}_{2}$ for $3 \mathrm{~h}$ and a cluster of mitochondria and position of cytochrome $\mathrm{c}$ are presented in Fig. 4. The integrated Raman intensities of the $\mathrm{CH}$ stretching mode $\left(2800-3000 \mathrm{~cm}^{-1}\right)$ indicate the protein, lipid, and carbohydrate distribution in the cells. Compared with the bright-field image, an intracellular image constructed based on the $\mathrm{CH}$ band is achieved. The map of correlation coefficients between cytochrome $c$ and the cell Raman spectra is superposed on cells and the white clusters of mitochondria. The image shows that the cytochrome $\mathrm{c}$ is located on the mitochondria

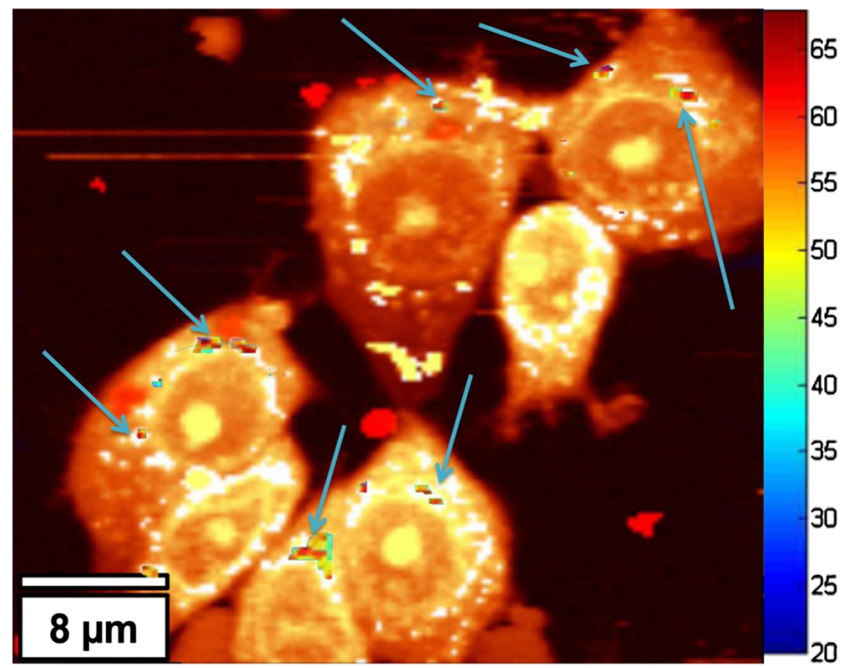

Figure 4. Composite image of MCF-7 cells incubated with $2 \mu \mathrm{g} \mathrm{ml}^{-1}$ of $\mathrm{TiO}_{2}$ for $3 \mathrm{~h}$. The integrated Raman intensities of $\mathrm{CH}$ stretching mode $\left(2800-3000 \mathrm{~cm}^{-1}\right)$ give a representation of the protein, lipid, and carbohydrate distribution in the cells. Map of correlation coefficients between cytochrome $c$ and the cell Raman spectra is superposed on cells and white cluster of mitochondria. The cytochrome $c$ is located within the mitochondria cluster. Cytochrome $\mathrm{c}$ position is marked with arrows. 
cluster. Cytochrome c position is marked with arrows. The gradual time-dependent diffusion of titanium dioxide is presented in Fig. 5. Confocal Raman images formed by the integrated Raman intensities of the $\mathrm{CH}$ stretching mode region $\left(2800-3000 \mathrm{~cm}^{-1}\right)$ of TERT cells incubated with $2 \mu \mathrm{g} \mathrm{ml}^{-1}$ titanium dioxide at 3, 9, and $24 \mathrm{~h}$. The white arrows marked the position of $\mathrm{TiO}_{2}$ (green spots). Particles after $3 \mathrm{~h}$ of incubation are mostly close to cell membrane (Fig. 5(a)); after $9 \mathrm{~h}$ of incubation, $\mathrm{TiO}_{2}$, penetrates in cytoplasm (Fig. 5(b)); and after $24 \mathrm{~h}$, some $\mathrm{TiO}_{2}$ are found in nucleus (Fig. 5(c)).

\section{Discussion}

The work presented here demonstrates the ability of confocal Raman microscopy to trace nanoparticles inside living cells without the use of any dye or label. This noninvasive method was used here to localize the nanoparticle $\mathrm{TiO}_{2}$ in a subcellular environment. This was possible by combining confocal Raman microscopy with post-measurement data analysis. Along with offering insight into the characteristics of the intracellular behavior of nanoparticles, Raman imaging enables investigating the penetration behavior of $\mathrm{TiO}_{2}$ particles into live cells. Taking into account our DLS measurements that show that nanoparticles in dry powder have a mean size of $25 \mathrm{~nm}$, whereas they form aggregates of about $200 \mathrm{~nm}$ in water, it has to be emphasized that the intracellular distributions we see in the Raman images belong to $\mathrm{TiO}_{2}$ aggregates and not to individual nanoparticles. Obviously, the biological impact of aggregates regarding to their physico-chemical properties is different. ${ }^{[48]}$ Because the confocal Raman microscope has a resolution of $300 \mathrm{~nm}$, close to the light diffraction limit, we were not able to observe individual aggregates. The intracellular aggregates observed by us had sizes in the range of $0.5-2 \mu \mathrm{m}$. Taking into account these large sizes and the unfavorable electrostatic interactions between the particles and the negatively charged cell membrane, we can speculate that they enter the membrane aided by the serum proteins adsorbing onto the nanoparticles surface and dictating their internalization via receptor-mediated endocytosis. $^{[49,50]}$ Our investigation addressed also apoptosis, a process resulting from the activation of caspases by which the cell actively participates in its own destruction. ${ }^{[51,52]}$ The key factor in apoptosis is the release of cytochrome $\mathrm{c}$ by mitochondria; hence, cell apoptosis can be detected if cytochrome $\mathrm{c}$ is outside the mitochondria. The mitochondrial size, as determined by electron microscopy, is about $1 \mu \mathrm{m}$ long and $0.5 \mu \mathrm{m}$ wide. Mitochondria can be studied. Compared with electron microscopy involving extensive sample preparation and fluorescence microscopy comprising staining mitochondria using fluorescent dyes that might disturb the normal cell cycle, confocal Raman microscopy overcomes these problems and provides a noninvasive method to study mitochondria in living cells. Although the spectral contrasts between the cellular components are relatively small, as they are very similar in terms of Raman vibrations, it is possible to reveal very small differences between the various parts of the cell, ${ }^{[45,53]}$ based on the Raman reference spectra of mitochondria, cytoplasm, and nuclei that have been previously published. ${ }^{[21]}$ Detection of $\mathrm{TiO}_{2}$ nanoparticles in cells revealed a gradual time-dependent diffusion of the nanoparticles over the entire cell. To trace the nanoparticles in the cells, the first step was to record the Raman spectrum of pure nanoparticles comprising very specific peaks localized far from the peaks of cellular components. Therefore, our application of the KMCA enabled us to locate the $\mathrm{TiO}_{2}$ nanoparticles and the different cellular components, such as the nucleus, the cytoplasm, and the mitochondria.

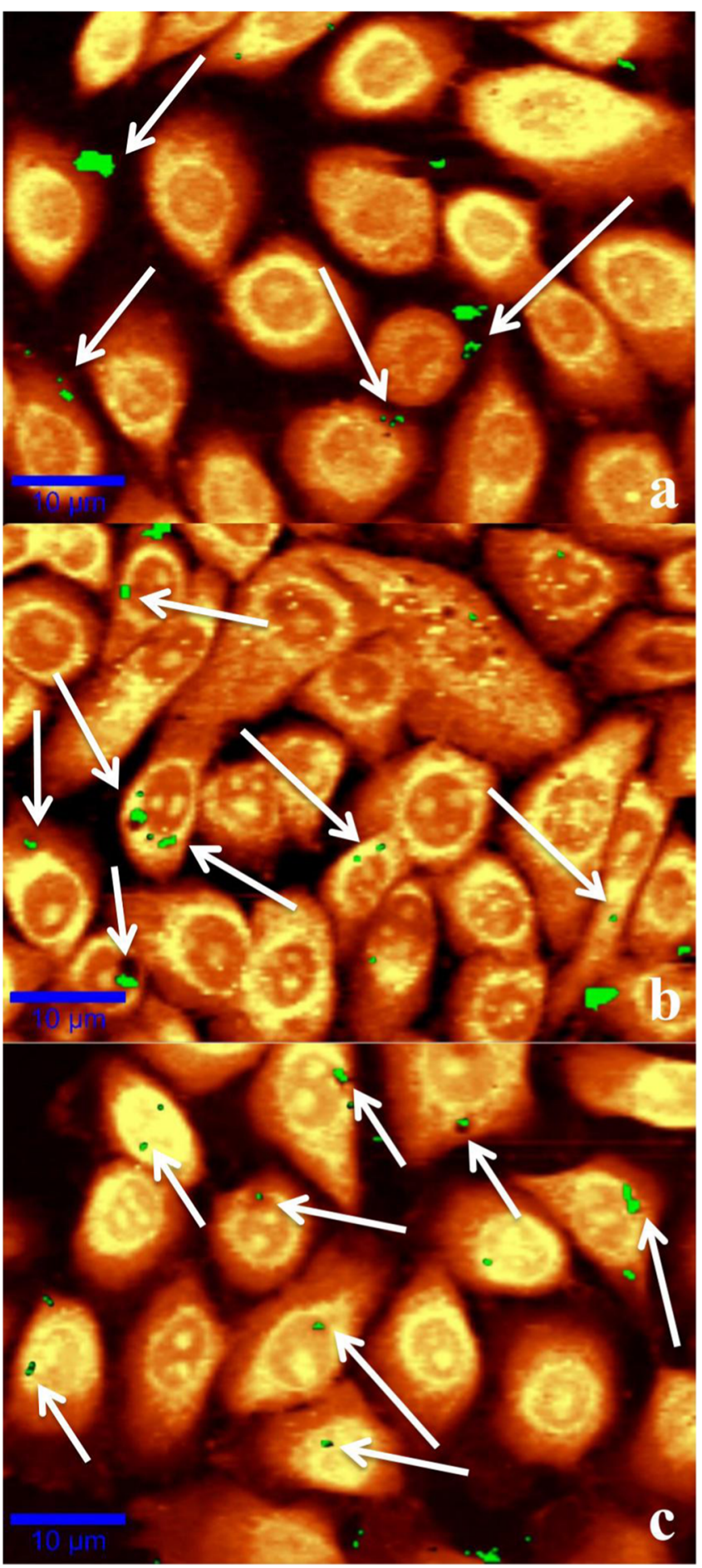

Figure 5. Gradual time-dependent diffusion of titanium dioxide based on confocal Raman images formed by integrated Raman intensities of $\mathrm{CH}$ stretching mode region $\left(2800-3000 \mathrm{~cm}^{-1}\right)$. TERT cells incubated with $2 \mu \mathrm{g} \mathrm{ml}^{-1}$ titanium dioxide at (a) $3 \mathrm{~h}$, (b) $9 \mathrm{~h}$, and (c) $24 \mathrm{~h}$. The white arrows marked the position of $\mathrm{TiO}_{2}$ (green spots). Particles after $3 \mathrm{~h}$ of incubation are mostly close to cell membrane (a), after $9 \mathrm{~h}$ of incubation $\mathrm{TiO}_{2}$ penetrate in cytoplasm (b), and after $24 \mathrm{~h}$ some $\mathrm{TiO}_{2}$ are found in nucleus (c).

By measuring the cytochrome $\mathrm{c}$ spectrum as a reference and comparing it with all the other Raman image spectra of the cell, we could produce a correlation coefficient map of cytochrome c. 'The correlation coefficient as a technique to monitor cytochrome c should be treated very carefully. The similarity of the cell 
organelles Raman spectra might be confusing to localize them. This technique is considered an unsupervised method. Meanwhile, the spectra of most correlated and uncorrelated spectra should be compared with the reference spectrum to check the validities of the results. Purity of the reference spectrum of cytochrome also $c$ should be considered as a critical point.' At the concentration of $\mathrm{TiO}_{2}$ nanoparticles and contact time used in this study, no cytochrome $\mathrm{c}$ release was detected indicating that no cellular apoptosis has been occurred.

\section{Conclusion}

This study demonstrates the ability of the noninvasive, label-free confocal Raman microscopy to localize $\mathrm{TiO}_{2}$ nanoparticles in a cellular environment, based on their chemical fingerprint and advanced data analysis. Because of various data analysis, we were able to localize different parts of the living MCF-7 and TERT cells, importantly the mitochondria. Based on the reference spectrum of cytochrome c, a correlation coefficient map was constructed, indicating its position within the cells. A comparison with the clusters corresponding to mitochondria indicates that cytochrome $\mathrm{c}$ is inside the mitochondria, suggesting that cells exposed to $2 \mu \mathrm{g} \mathrm{ml}^{-1}$ concentrated $\mathrm{TiO}_{2}$ nanoparticles for $3 \mathrm{~h}$ do not undergo apoptosis. Raman confocal microscopy can potentially locate and identify nanoparticles within cells, and apoptosis via the mitochondrial pathway could be detected. Our study demonstrates that the combination of confocal Raman microscopy and advanced post-measurement analysis provides multiple information from the same set of data, opening the way for promising new paths to study live cells in a label-free manner.

\section{Acknowledgements}

The authors thank Professor Elias Perez from UASLP (MX) for providing samples and for his support. The authors also acknowledge the support of a Balaton program (Hubert Curien Partnership - PHC) between France and Hungary.

\section{References}

[1] S. C. o. E. a. N. I. H. Risks. European Commission Health \& Consumers DG, 2009.

[2] G. Oberdorster, E. Oberdorster, J. Oberdorster, Environ. Health Perspect. 2005, 113, 823.

[3] N. A. Monteiro-Riviere, K. Wiench, R. Landsiedel, S. Schulte, A. O. Inman, J. E. Riviere, Toxico. Sci. 2011, 123, 264.

[4] D. L. Cochran, J. Periodontol. 1999, 70, 1523.

[5] X. Qu, X. Huang, K. Dai, Arch. Orthop. Trauma. Surg. 2011, 131, 1573.

[6] P. Senna, A. Antoninha Del Bel Cury, S. Kates, L. Meirelles, Clin. Implant Dent. Relat. Res. 2013, DOI: 10.1111/cid.12167.

[7] T. Jarmar, A. Palmquist, R. Brånemark, L. Hermansson, H. Engqvist, P. Thomsen, Clin. Implant Dent. Relat. Res. 2008, 10, 11.

[8] P. Boffetta, V. Gaborieau, L. Nadon, M. F. Parent, E. Weiderpass, J. Siemiatycki, Scand. J. Work Environ. Health 2001, 27, 227.

[9] R. Landsiedel, E. Fabian, L. Ma-Hock, W. Wohlleben, K. Wiench, F. Oesch, B. van Ravenzwaay, Arch. Toxicol. 2012, 86, 1021.

[10] Z. N. Gheshlaghi, G. H. Riazi, S. Ahmadian, M. Ghafari, R. Mahinpour, Acta Biochim. Biophys. Sin. (Shangai) 2008, 40, 777.

[11] R. Cai, Y. Kubota, T. Shuin, H. Sakai, K. Hashimoto, A. Fujishima, Cancer Res. 1992, 52, 2346

[12] J. Dorney, F. Bonnier, A. Garcia, A. Casey, G. Chambers, H. J. Byrne, Analyst 2012, 137, 1111.
[13] A. M. Schrand, J. J. Schlager, L. Dai, S. M. Hussain, Nat. Protoc. 2010, $5,744$.

[14] M. J. Clift, B. Rothen-Rutishauser, D. M. Brown, R. Duffin, K. Donaldson, L. Proudfoot, K. Guy, V. Stone, Toxicol. Appl. Pharmacol. 2008, 232, 418.

[15] A. Salvati, C. Aberg, T. dos Santos, J. Varela, P. Pinto, I. Lynch, K. A. Dawson, Nanomedicine 2011, 7, 818.

[16] R. M. Zucker, K. M. Daniel, Methods Mol. Biol. 2012, 906, 497.

[17] R. M. Zucker, E. J. Massaro, K. M. Sanders, L. L. Degn, W. K. Boyes, Cytometry A 2010, 77, 677.

[18] L. Ahlinder, B. Ekstrand-Hammarstrom, P. Geladi, L. Osterlund, Biophys. J. 2013, 105, 310.

[19] M. M. Mariani, P. J. Day, V. Deckert, Integr. Biol. (Camb) 2010, 2, 94.

[20] K. E. Shafer-Peltier, A. S. Haka, J. T. Motz, M. Fitzmaurice, R. R. Dasari, M. S. Feld, J. Cell. Biochem. Suppl. 2002, 39, 125.

[21] C. Matthaus, T. Chernenko, J. A. Newmark, C. M. Warner, M. Diem, Biophys. J. 2007, 93, 668.

[22] C. Matthaus, A. Kale, T. Chernenko, V. Torchilin, M. Diem, Mol. Pharm. 2008, 5, 287.

[23] K. Klein, A. M. Gigler, T. Aschenbrenner, R. Monetti, W. Bunk, F. Jamitzky, G. Morfill, R. W. Stark, J. Schlegel, Biophys. J. 2012, 102, 360.

[24] B. Bird, C. Matthäus, M. Miljković, T. Chernenko, M. Romeo, M. Diem, Meth Cell Biol 2008, 89, 275.

[25] J. Zhao, L. Bowman, X. Zhang, V. Vallyathan, S. H. Young, V. Castranova, M. Ding, J. Toxicol. Environ. Health A 2009, 72, 1141.

[26] Y. Zhang, W. Yu, X. Jiang, K. Lv, S. Sun, F. Zhang, J. Mater. Sci. Mater. Med. 2011, 22, 1933.

[27] R. K. Shukla, A. Kumar, D. Gurbani, A. K. Pandey, S. Singh, A. Dhawan, Nanotoxicology 2013, 7, 48

[28] T. J. Collins, M. J. Berridge, P. Lipp, M. D. Bootman, EMBO J. 2002, $21,1616$.

[29] S. Y. Jeong, D. W. Seol, BMB Rep. 2008, 41, 11.

[30] M. M. Martinez, R. D. Reif, D. Pappas, Anal. Methods 2010, 2, 996.

[31] Y. Shi, F. Wang, J. He, S. Yadav, H. Wang, Toxicol. Lett. 2010, 196, 21.

[32] V. P. Zharov, E. I. Galanzha, V. V. Tuchin, Cytometry A 2007, 71, 191.

[33] H. Salehi, L. Derely, A.-G. Vegh, J.-C. Durand, C. Gergely, C. Larroque, M.-A. Fauroux, F.-J.-G. Cuisinier, Appl. Phys. Lett. 2013, 102, 113701.

[34] A. S. Levenson, V. C. Jordan, Cancer Res. 1997, $57,7$.

[35] B. Ohtani, O. O. Prieto-Mahane, D. Li, R. Abe, J. Photochem. Photobiol. A 2010, 216, 4.

[36] H. Jensen, J. H. Pedersen, J. E. Jørgensen, J. S. Pedersen, K. D. Joensen, S. B. Iversen, E. G. Søgaard, J. Exp. Nanosci. 2006, 1, 18.

[37] A. Bootz, V. Vogel, D. Schubert, J. Kreuter, Eur. J. Pharm. Biopharm. 2004, $57,369$.

[38] T. Dieing, O. Hollricher, J. Toporski, Confocal Raman Spectroscopy, ISBN 978-3-642-12521-8, 2010.

[39] Y. Fukuzaki, H. Sugawara, B. Yamanoha, S. Kogure, PLoS One 2013, 8, e70737.

[40] A. G. Anwer, M. E. Gosnell, S. M. Perinchery, D. W. Inglis, E. M. Goldys, Lasers Surg. Med. 2012, 44, 769.

[41] H. Salehi, E. Middendorp, I. Panayotov, P. Y. Collart Dutilleul, A. G. Vegh, S. Ramakrishnan, C. Gergely, F. Cuisinier, J. Biomed. Opt. 2013, 18, 56010.

[42] N. Uzunbajakava, A. Lenferink, Y. Kraan, E. Volokhina, G. Vrensen, J. Greve, C. Otto, Biophys. J. 2003, 84, 3968.

[43] J. MacQueen. In Fifth Berkeley Symposium on Mathematical Statistics and Probability (Eds: Le Cam L. M., Neyman J.). University of California Press: Berkeley, USA, 1967; .p 281.

[44] R. Ranga Raj, M. Punithavalli, IJANA 2012 4, 1578.

[45] M. Miljkovic, T. Chernenko, M. J. Romeo, B. Bird, C. Matthaus, M. Diem, Analyst 2010, 135, 2002.

[46] M. O. Hengartner, Nature 2000, 407, 770

[47] M. Okada, N. I. Smith, A. F. Palonpon, H. Endo, S. Kawata, M. Sodeoka, K. Fujita, Proc. Natl. Acad. Sci. U. S. A. 2012, 109, 28.

[48] H. Shi, R. Magaye, V. Castranova, J. Zhao, Part. Fiber Toxicol. 2013, 10, 15.

[49] Z. E. Allouni, P. J. Hol, M. A. Cauqui, N. R. Gjerdet, M. R. Cimpan, Toxicol. In Vitro 2012, 26, 469.

[50] B. D. Chithrani, W. C. Chan, Nano Lett. 2007, 7, 1542.

[51] K. L. Adams, J. D. Palmer, Mol. Phylogenet. Evol. 2003, 29, 380.

[52] G. Burger, M. W. Gray, B. F. Lang, Trends Genet. 2003, 19, 709.

[53] C. Matthaus, S. Boydston-White, M. Miljkovic, M. Romeo, M. Diem, Appl. Spectrosc. 2006, 60, 1 